\title{
Audit of Referrals to an Ophthalmic Outpatient Clinic of a Tertiary Eye Care Centre in a Developing Country
}

\author{
${ }^{1}$ BI Eze, FMCOphth, FWACS, FICS, ${ }^{1}$ OI Okoye, FMCOphth, FICS, ${ }^{1}$ FC Maduka-Okafor, \\ FMCOphth,FICS, ${ }^{2}$ EN Aguwa, FMCPH, FWACP \\ ${ }^{1}$ Department of Ophthalmology, University of Nigeria Teaching Hospital (UNTH), PMB 01129, Ituku/Ozalla, Enugu, Nigeria \\ ${ }^{2}$ Department of Community Medicine, University of Nigeria Teaching Hospital (UNTH), PMB 01129, Ituku/Ozalla, Enugu, \\ Nigeria
}

\section{ABSTRACT}

Objectives: To determine the referral pattern and assess the quality and accuracy of referral letters to the ophthalmic outpatient clinic of University of Nigeria Teaching Hospital, Enugu.

Methods: This study is a prospective cross-sectional survey of all new ophthalmic referrals to the ophthalmic outpatient clinic at University of Nigeria Teaching Hospital, Enugu between $1^{\text {st }}$ July 2006 and $31^{\text {st }}$ December 2006.

Patients' referral letters and clinical case notes provided information on demography, referral source, referral diagnosis, definitive diagnosis and quality of referral letter. The number of ophthalmic outpatient consultations during the study period was obtained from clinic records. Data were analysed with the Statistical Package for Social Sciences to generate frequency and percentage distributions. The chi-square test was used for inter-group comparison at $\mathrm{p}<0.05$.

Results: There were 461 new ophthalmic referrals comprising $217(47.1 \%)$ males and $244(52.9 \%)$ females. The rate of referrals based on gender was not significant $(\mathrm{p}=0.3044)$. The age range was 3-67 years (mean $=18.5$ years, $S D=0.6)$. More adults ( $>16$ years) than children $(\leq 16$ years) were referred $(\mathrm{p}<0.05)$.

New referrals constituted $18.2 \%$ of the 2,531 ophthalmic outpatient consultations. After definitive diagnosis, refractive error (19.9\%) and allergic conjunctivitis $(17.4 \%)$ were the main ocular diseases leading to referral. Fifty-two percent of referral letters satisfied the provision of clinical information criteria, $2.8 \%$ satisfied the formulation of specific request criteria, while $1.9 \%$ satisfied both. Ophthalmologist-initiated referrals were most accurate $(78.6 \%)$, while referrals from paediatricians were the least accurate (13.9\%). The majority of patients 256 (55.7\%) were referred by GPs while ophthalmologists referred the minority-14 (3.0\%).

Conclusions: The majority of the referral letters were of poor quality, low accuracy, and inappropriate. To reverse this trend, local educational interventions which incorporate clinical correspondence into undergraduate medical training curriculum, and the organization of workshops on clinical information exchange for GPs, specialists and paramedical personnel are recommended.

Key words: audit, referrals, ophthalmic outpatient, Enugu, Nigeria

\section{INTRODUCTION}

Patient referral is a fundamental component of health care delivery system which bridges the vertical health care interface gap between different levels of care and the horizontal health care interface gap between medical specialties ${ }^{1}$.The referral instrument, usually a referral letter, serves as source of reference, evidence of process of informed consent, and medico-legal record. ${ }^{2}$ Additionally, it has important security implications for the referring and the recipient medical personnel, and safety implications for the patient. ${ }^{2}$

Physical referral letters entailing a standard outpatient consultation, and electronic referral (telephone, fax, e-mail \& telemedicine, i.e., virtual outreach consultation) are the currently available modes of referral. The choice of referral mode is determined by availability, cost, clinical state of the patient and the underlying reason for referral. ${ }^{3,4}$ While a physical referral letter (hard copy) is the preferred mode in developing countries, emphasis is shifting in the direction of electronic clinical information exchange in developed countries where there is unhindered access to information technology.

The standard indications for patient referral include patient's wish, re-assurance of patient and referring medical personnel, need for specific investigations and diagnosis, advice on management, and medical second opinion. ${ }^{6,7}$ Consequently, to achieve the above objectives, referrals must be accurate, appropriate, effective, and beneficial to the referral medical personnel. ${ }^{8}$

Grol et al. ${ }^{7}$ and Jiwa ${ }^{9}$ emphasized the need for more health services research on clinical information exchange across the health care interface to improve the overall quality of health

${ }^{*}$ Correspondence: Dr Boniface Ikenna Eze, Department of Ophthalmology, University of Nigeria Teaching Hospital (UNTH), PMB 01129, Ituku/Ozalla, Enugu, Nigeria • E-mail: xy3165767@yahoo.com 
care by maintaining continuity of care during the journey between levels and specialties of care. Furthermore, the determination of the pattern of referrals to any health care facility assists the local health care planners in optimizing human and material resources during planning for promotive, preventive, curative and rehabilitative health care. Consequently, this study was intended to determine the pattern, accuracy and quality of referrals to the ophthalmic outpatient clinic of University of Nigeria Teaching Hospital (UNTH), Enugu.

\section{METHODS}

Established in 1971, the University of Nigeria Teaching Hospital (UNTH), Enugu, located in the South East geopolitical zone of Nigeria is one of the first generation tertiary health care facilities in Nigeria.. With an inpatient bed capacity of 661 and a heavy traffic of outpatients, it takes referrals from hospitals located in the South East geopolitical zone and beyond. Between $1^{\text {st }}$ July 2006 and $31^{\text {st }}$ December 2006, all consecutive new patients referred to the ophthalmic outpatient clinic of the hospital were included in this study.

The quality of referral letters received was assessed based on guidelines obtained from international literature. ${ }^{7,10}$ The referral letters were considered to have satisfied the 'provision of clinical information' criterion ( $1^{\text {st }}$ order criteria) when at least four of the following clinical items of information were provided:

1. Patient symptoms

2. Findings on previous examination

3. Whether or not investigation was performed

4. Whether or not treatment was given

5. Current medication

Provision of at least one of the following satisfied the 'formulation of specific request' criterion ( $2^{\text {nd }}$ order criteria):

1. Request for definitive diagnosis

2. Request for treatment

3. Request for management plan

Patients' demographic data and the definitive diagnosis arrived at by the consulting ophthalmologist were obtained from their clinical case notes at the end of consultation. Data were collected using a structured, pre-tested questionnaire, filled in and analysed using the Statistical Package for Social Science (SPSS) computer software version 12.0.1 for Windows ${ }^{11}$ to generate frequency, percentage, proportion, and distribution. Statistical tests for significant inter-group differences were done with the chi-square of the Graph Pad Prism software with significance level at $\mathrm{p}<0.05, \mathrm{df}=1$.

During the same period, the number of ophthalmic outpatient consultations was obtained from clinic records.

\section{STUDY DEFINITIONS}

Referral diagnosis: Aetiology of the patients' eye condition explicitly or implicitly stated in the referral letter.
Definitive diagnosis: Aetiology of patient's eye condition arrived at after exhaustive clinical evaluation by the ophthalmologist. In patients with multiple referral or definitive diagnoses, the single most sight-threatening condition requiring urgent therapeutic intervention was selected. ${ }^{12}$

Structured (form) referral letter: Pre-typed referral letter containing empty spaces for filling in patient's clinical information, and requests by the referral health personnel.

Unstructured (non-form) referral letter: Handwritten, the letter contains patient's clinical information and requests.

Inappropriate referral: Referral to higher level eye care facility of cases amenable to treatment at lower level eye care centre.

\section{RESULTS}

Four hundred and eighty-four new ophthalmic patients were seen at the UBTH ophthalmic outpatient clinic during the study period. Of these, 23 who were self-referred (without any referral letter) were excluded from the study. Of the remaining 461 (ie, 53.0\%), 244 presented structured referral (form) letters, while $217(47.0 \%)$ had unstructured (non-form) referral letters. No other mode of referral was encountered.

New ophthalmic referrals constituted $18.2 \%$ of the 2,531 ophthalmic consultations during the study period. This can be further broken down into 244 (52.9\%) women and 217 (47.1\%) men, giving a male to female ratio of 1:1.1. This comprised 381 $(82.6 \%)$ adults (age $>16 y e a r s)$ and $80(17.4 \%)$ children. The age range was 3-67 yrs (mean 18.5 years, $\mathrm{SD}=0.6$ ) (table 1 ).

Table 1. Age / sex distribution of 461 new patients

\begin{tabular}{c|c|c|c|c}
\hline Age group years & M & F & Total & Percentage \\
\hline$<16$ & 37 & 40 & 77 & 16.7 \\
$17-26$ & 49 & 55 & 104 & 22.6 \\
$27-36$ & 24 & 28 & 52 & 11.3 \\
$37-46$ & 25 & 27 & 52 & 11.3 \\
$47-56$ & 40 & 46 & 86 & 18.7 \\
$57-66$ & 27 & 31 & 58 & 12.5 \\
$>66$ & 15 & 17 & 32 & 6.9 \\
\hline Total & 217 & 244 & 461 & 100 \\
\hline
\end{tabular}

There was no statistically significant difference between gender $(52.9 \%$ vs $47.1 \%$, p=0.304); however, significantly more adults than children $(82.6 \%$ vs $17.4 \%, \mathrm{p}<0.05)$ were referred during the study period. Refractive error (19.9\%) and allergic conjunctivitis (17.4\%) were the leading definitive diagnoses amongst the new patients referred (table 2).

Twenty-four (5.2\%) referral letters satisfied the provision of clinical information criteria, $13(2.8 \%)$ satisfied the formulation of specific request criteria while $9(1.9 \%)$ satisfied both (table 3). 
Table 2. Definitive diagnosis in 461 new patients

\begin{tabular}{l|c|c}
\hline Definitive diagnosis & Number & Percentage \\
\hline Refractive error & 92 & 19.9 \\
Allergic conjunctivitis & 80 & 17.4 \\
Cataract & 62 & 13.4 \\
Infection/inflamation & 35 & 7.6 \\
Maculopathy & 30 & 6.5 \\
Retinal vascular disease & 25 & 5.4 \\
Glaucoma & 22 & 4.8 \\
Trauma & 21 & 4.6 \\
Pterygium & 19 & 4.1 \\
Congenital defect & 15 & 3.3 \\
Chalazion & 13 & 2.8 \\
Tumour & 13 & 2.8 \\
Strabismus & 10 & 2.8 \\
Others & 24 & 5.2 \\
\hline Total & 461 & 100.0 \\
\hline
\end{tabular}

Table 3. Quality of referral letters

\begin{tabular}{l|cc}
\hline Quality criteria & $\begin{array}{c}\text { Number where } \\
\text { provided }\end{array}$ & $\begin{array}{c}\text { Percentage of } \\
\text { new patients } \\
(\mathrm{n}=461)\end{array}$ \\
\hline $\begin{array}{l}\text { Provision of clinical } \\
\text { information criteria }\end{array}$ & & \\
$\begin{array}{l}\text { Patients symptoms } \\
\begin{array}{l}\text { Findings from previous } \\
\text { examination }\end{array}\end{array}$ & 26.7 \\
$\begin{array}{l}\text { Whether or not } \\
\text { investigations were } \\
\text { performed }\end{array}$ & 108 & \\
$\begin{array}{l}\text { Whether or not treatment } \\
\text { was given }\end{array}$ & 20 & \\
$\begin{array}{l}\text { Information on current } \\
\text { medication }\end{array}$ & 400 & \\
$\begin{array}{l}\text { Formulation of specific } \\
\text { request criteria } \\
\begin{array}{l}\text { Request for feedback on } \\
\text { diagnosis, treatment or } \\
\text { management plan }\end{array}\end{array}$ & 48 & \\
\hline
\end{tabular}

Ophthalmologist-initiated referrals were the most accurate - 78.6\%; while referrals from paediatricians were the least accurate $-13.9 \%$. GPs referred the highest number of patients - $256(58.7 \%)$ while ophthalmologists referred the lowest number - 14 (3.8\%) (see table 4$)$.
Table 4. Accuracy of referral of 461 new patients

\begin{tabular}{|c|c|c|c|c|}
\hline \multirow[b]{2}{*}{$\begin{array}{l}\text { Referral } \\
\text { source }\end{array}$} & \multicolumn{3}{|c|}{$\begin{array}{l}\text { Agreement between referral } \\
\text { and definitive diagnosis }\end{array}$} & \multirow[b]{2}{*}{$\begin{array}{l}\text { Total } \\
\text { referral }\end{array}$} \\
\hline & $\begin{array}{c}\begin{array}{c}\text { Agree- } \\
\text { ment }\end{array} \\
\text { no }(\%)\end{array}$ & $\begin{array}{c}\text { No } \\
\text { agree- } \\
\text { ment } \\
\text { no } \quad(\%)\end{array}$ & $\begin{array}{l}\text { No referral } \\
\text { diagnosis } \\
\text { no } \quad(\%)\end{array}$ & \\
\hline $\begin{array}{l}\text { Gen prac. } \\
\text { nurse/ }\end{array}$ & $41(16.0)$ & 81 (31.6) & $134(52.3)$ & $256(55.5)$ \\
\hline midwife & $9 \quad(18.0)$ & $14(28.0)$ & $27 \quad(54.0)$ & $50 \quad(10.8)$ \\
\hline Paediatric & $5 \quad(13.9)$ & $10(27.8)$ & $21 \quad(58.5)$ & $36 \quad(7.8)$ \\
\hline Physician & $6 \quad(17.0)$ & $9(26.8)$ & $20 \quad(58.8)$ & $(7.6)$ \\
\hline Surgeon & $4 \quad(16.7)$ & $7(29.2)$ & $13(54.2)$ & $(5.2)$ \\
\hline Gynaecol & $3(18.8)$ & $3(18.8)$ & $10 \quad(62.5)$ & $(3.5)$ \\
\hline Optomet & $10(62.5)$ & $5(13.3)$ & $1 \quad(6.3)$ & $(3.5)$ \\
\hline Ophthal & 11 (78.6) & $3(24.4)$ & $0 \quad(0.0)$ & $(3.0)$ \\
\hline Others & $1 \quad(7.1)$ & $3(21.4)$ & $10 \quad(71.4)$ & (3.0) \\
\hline TOTAL & $90(19.5)$ & 135 (29.3) & $236(51.2)$ & $461 \quad(100)$ \\
\hline
\end{tabular}

\section{DISCUSSION}

The number of new ophthalmic referrals to the ophthalmic outpatient clinic in this study is small when compared with the findings in the audit of paediatric ophthalmic referrals to the same centre reported by Onwasigwe et al. ten years earlier. ${ }^{13}$ This may be explained by the exclusion of ophthalmic emergency referrals to the accident and emergency unit, and the shorter duration of the present study. Furthermore, the relocation of UNTH to its present permanent site with attendant barriers to access imposed by distance may also account for this shortfall.

Consistent with a previous report, ${ }^{13}$ more female than male ophthalmic patients were referred to our centre during the study period. However, despite the absence of an overall statistically significant difference between the number of male vs female patients $(52.9 \%$ vs $47.1 \%, \mathrm{p}=0.304)$ in the present report, the majority $(82 \%)$ of the 42 patients referred for cosmetic reasons (pterygium 19; chalazion 13; and strabismus 10) were women. It appears that women are more likely to treat eye diseases which have a cosmetic component than their male counterparts. ${ }^{13,14}$

Refractive error (19.9\%) and allergic conjunctivitis $(17.4 \%)$ were the leading indications for ophthalmic referral in this study. This is similar to the observations by Onwasigwe et al. ${ }^{13}$ but differs from the report by Greiner et al. ${ }^{12}$ who had cataract and medical diseases of the retina as their leading indications for referral. Unfortunately, the leading indications for referral in the present study are 'inappropriate referrals' which could have been managed effectively in lower cadre eye centres were appropriate ophthalmic manpower available. As obtains in similar settings in sub-Saharan Africa, ${ }^{15}$ the paucity of all cadres of 
eye care manpower may explain this observation. This referral pattern emphasizes the need for eye care planners to provide adequate human and material resources for treatment of these common eye diseases at primary and secondary levels of eye care.

GP-initiated referrals constituted $55.7 \%$ while ophthalmologist-initiated referrals accounted for only $3.0 \%$. This is similar to a report by Wang-yu Dong et al., ${ }^{16}$ but differs from that of Harrison and colleagues. ${ }^{17}$ In Nigeria, like in other developing countries, GPs far outnumber specialist medical personnel, ophthalmologists inclusive. Furthermore, the available ophthalmologists are predominately located in urban centres. This scenario makes them relatively unavailable as potential initiators of referral letters. Furthermore, in the study centre, ophthalmic self-referrals are usually routed through the General Outpatient Department (GOPD) before presentation at the ophthalmic outpatient clinic. The GOPD is manned by GPs only, thus making them the major referral source to the eye clinic. Of the 256 GP-initiated referrals in this study, the GOPD derived referrals accounted for $68 \%$. This finding suggests that GPs should be target participants in any training intervention on referrals to ophthalmic and other specialist outpatient clinics.

Quality assessment of the letters received during this study revealed a poor performance rating when compared with the work by Grol et al. ${ }^{7}$ Provision of clinical information score in this study was $5.2 \%$ compared to $35 \%$ in the Grol et al. report. The specific request formulation score in this study was $2.8 \%$ compared to $59 \%$ in the Grol et al. report while the overall score was $1.9 \%$, compared to $20 \%$ in the Grol et al. report. ${ }^{7}$

The common practice of writing referral letters in a hurry, coupled with delegation of the duty of writing referral letters to inexperienced junior colleagues (often occasioned by excess outpatient workload) may account for the poor performance rating of the referral letters received. Additionally, writing referral letters long after the patient has left the clinic, coupled with the poor and imprecise content of such letters may also have contributed to the poor quality performance scores observed in this study. These may explain the surprisingly low quality scores of the referral letters, despite the high percentage of structured (form) referral letters (53.0\%) which are adjudged superior to unstructured (non-form) referral letters (47.0\%) in terms of clinical information content. ${ }^{18,19}$ This has adverse implications for the quality of eye care during the transition between the levels of eye care as crucial clinical, laboratory, and therapeutic baseline information on the referred patients are poorly documented.

The 19.5\% referral accuracy (percentage 'correct' diagnosis) documented in this study compares with $20.0 \%$ reported by Onwasigwe et al., but differs from the positive predictive value of 0.43 , which translates to referral accuracy of $43.0 \%$, for optometrist-initiated referrals to glaucoma clinic reported by Theodossiades and Murdoch. ${ }^{20}$ While
Onwasigwe and co-workers studied referrals from various sources to a general ophthalmology clinic, as was the case with this study, Theodossaides and Murdoch restricted their study to optometrist-initiated referrals to glaucoma clinic. Their comparatively higher accuracy score may be attributed to the greater knowledge of eye care by optometrists, compared with other medical personnel, who had no further training in ophthalmology beyond their short-term undergraduate ophthalmology exposure or during rotation as housemen. This study seems to spotlight the inadequacy, in duration and training content, of the undergraduate ophthalmology training curriculum.

Expectedly, indicative of their formal training in eye care, the accuracy of referrals by source was highest for ophthalmologists (78.6\%); followed by optometrists (62.5\%); and lowest for paediatricians $(13.9 \%)$. Paediatricians are probably under-equipped in knowledge, skill and material resources to diagnose the myriad of paediatric ophthalmic diseases they encounter routinely in practice. Our result cannot be compared with the findings of Bell and $\mathrm{O}^{\prime} \mathrm{Brien}^{21}$ who reported $96 \%$ referral diagnosis accuracy for optometrists because of the selectivity of their work for glaucoma-related referrals.

\section{CONCLUSION}

Apart from provision of information on the patient's symptoms, the majority of referral letters seen in this study were of poor quality and inaccurate. In addition, a majority of the referrals were inappropriate. It is recommended that the undergraduate ophthalmology training curriculum be reviewed with the aim of equipping trainees with appropriate theoretical knowledge and clinical skills to manage common eye diseases. Furthermore, to acquire adequate skills necessary to communicate effectively, we suggest regular clinical communication workshops for medical and paramedical personnel with special emphasis on GPs. ${ }^{8,12}$

The high number of refractive error and allergic eye disease reported in the referral letters in this study, spotlights the areas of need for future deployment of human and material resources at the secondary level of eye care, to ensure optimal impact of eye care delivery programmes.

Further health services research is urgently needed in our local environment to enhance the quality of eye health care at the health care interface.

\section{ACKNOWLEDGEMENTS}

We acknowledge the assistance of the resident doctors in the Department of Ophthalmology, and nursing staff of the ophthalmic outpatient clinic at the University of Nigeria Teaching Hospital, Enugu during this study.

\section{REFERENCES}

1. Grimshaw JM, Winkens RA, Shirran L, Cunningham C, Mayhew A, Thomas R, Fraser C. Interventions to 
improve outpatient referrals from primary care to secondary care. Cochrane Database Syst Rev 2005 Jul 20; (3):CD005471.

2. Campbell B, Vanslembroek K, Whitehead E, Van de Wauwer C, Eifell R, Wyatt M, Campbell J. Views of doctors on clinical correspondence: questionnaire survey and audit of content of letters. BMJ 2004; 328: 1060-1.

3. Jones NP, Woud IC, Kwartz J. General practitioner referrals to an eye hospital; a standard referral form. J Roy Soc Med 1990; 8:770-2.

4. Wallace P, Barber J, Clayton W, Currell R, Fleming K, Garner P, et al. Virtual outreach: a randomized controlled trail and economic evaluation of joint teleconferenced medical consultations. Health Technology Assess 2004; 8(50).

5. Kumar KR, Yogesan K, Constable IJ. Teleophthalmology in India: Is it here to stay? Indian J. Ophthalmol 2003; 5(4): 295 - 6.

6. Coulter A, Noone A, Goldacre M. General practitioners referrals to outpatient clinics I. why general practitioners refer patients to specialist outpatient clinics. BMJ 1989; 299(6694): $304-6$.

7. Grol R, Rooijackers-Lemmers N, Van Kaathoven L, Wollershiem $\mathrm{H}$, Mokkink $\mathrm{H}$. Communication at the interface: do better referral letters produce better consultant replies? Br J Gen Pract 2003; 53: 217 - 219.

8. Tattersal MHN, Butow PN, Brown JE, Thompson JF. Improving doctors' letters. MJA 2002; 177: 516 - 520.

9. Jiwa M. Quality of referral letters. Br J Gen Pract 2003; 53(490): 406.

10. Newton J, Eccles M, Hutchinson A. Communication between general practitioners and consultants: what should their letters contain? BMJ 1992; 304: 821 - 824.

11. Statistical Package for Social Sciences (SPSS) Version 12.0.1 for Windows. Chicago; SPSS Inc, 2004.
12. Greiner K, McCormack K, Grant A, Forrester JV. The relative contributions of medical and surgical referrals to the workload in general ophthalmic practice. $\mathrm{Br} J$ Ophthalmol 2003; 87: 933 - 935.

13. Onwasigwe EN, Umeh RE, Onwasigwe CN, Aniebue PN. Referral pattern of children to the eye department of the University of Nigeria Teaching Hospital, Enugu. NJO 1996; 4(1): 5-6.

14. Claoue C, Foss A, Daniel R, Cooling B. Why are new patients coming to the eye clinic? An analysis of the relative frequencies of ophthalmic diseases amongst new patients attending hospital eye clinics in two separate locations. Eye 1997; 11(pt6): 865-8.

15. WHO: National vision 2020 Implementation Data. Available at: www.WHO.int/pbd/blindness/vision2020/regional data/en/ Date accessed: February 2009.

16. Wang Yu-Dong, Thompson JR, Goulstine DB, Rosenthal AR. Survey of initial referral of children to an ophthalmology department. Br J Ophthalmol 1990; 74: $650-653$.

17. Harrison RY, Wild JM, Hobley AJ. Referral pattern to an ophthalmic outpatient clinic by general practitioners and ophthalmic opticians and the role of these professionals in screening for ocular disease. BMJ 1988; 297(6657): $1162-7$.

18. Jenkins S, Arrol B, Hawken S, Nicholson R. Referral letters: are form letters better? Br J Gen Pract 1997; 47: $107-108$.

19. Dupont C. Quality of referral letters. Lancet 2002; 359: 1701.

20. Theodossiades J, Murdoch I. Positive predictive value of optometrist initiated referrals for glaucoma. Ophthalmic Physiol Optic 1999; 19(1): $62-67$.

21. Bell RW, $\mathrm{O}^{\prime}$ Brien C. Accuracy of referral to glaucoma clinic. Ophthalmic Physiol Optic 1997; 7(1): 7 - 11. 